\title{
Characterization of a piscirickettsiosis-like disease in Hawaiian tilapia
}

\author{
Michael J. Mauel ${ }^{1, *}$, Debra L. Miller ${ }^{1}$, Kendall Frazier ${ }^{1}$, Alan D. Liggett ${ }^{1}$, L. Styer ${ }^{1}$, \\ Dee Montgomery-Brock ${ }^{2}$, James Brock ${ }^{2}$
}

${ }^{1}$ Veterinary Diagnostic and Investigational Laboratory, College of Veterinary Medicine, The University of Georgia, PO Box 1389, Tifton, Georgia 31793, USA

${ }^{2}$ Aquaculture Development Program, Department of Agriculture, State of Hawaii, 1177 Alakea Street \#400, Honolulu, Hawaii 96813, USA

\begin{abstract}
In 1994, tilapia (Oreochromis mossambicus and Sarotherodon melanotheron) in wild and farmed populations on Oahu, Hawaii, USA, began to die of an unknown disease that was similar but not identical to piscirickettsiosis in salmonids. Only tilapia were affected. Diseased tilapia often swam erratically and had trouble staying at depth. Scattered cutaneous haemorrhage and exophthalmia were often noted. In many cases, fish were found dead with no clinical signs. Gills exhibited epithelial hyperplasia with severe multifocal consolidation of secondary lamellae. Multiple granulomas were observed in the gills, spleen, kidney, choroid gland and testes, but not in the liver. Tilapia mortalities occurred only during the cooler months (October to April) of the year and were not recorded during the warmer months (May to September). The mortalities declined with each successive year, after the 1994 outbreak, and currently losses are sporadic. Oxytetracycline-medicated feed reduced mortality. Cytologic examination of blood smears revealed moderate to large numbers of Gramnegative, pleomorphic, intracellular bacteria in rare circulating monocytes. Histologically, some predilection for nervous tissue and brain was observed. When viewed with transmission electron microscopy, pleomorphic coccoid bacteria, measuring $0.56 \pm 0.14 \times 0.7 \pm 0.20 \mu \mathrm{m}$, occurred free in the cytoplasm and within phagolysosomes. The organisms had a double cell wall, no defined nucleus and variable electron-dense and -lucent areas. Unlike Piscirickettsia salmonis, the agent of piscirickettsiosis, the Hawaiian tilapia Piscirickettsia-like organism (HTPLO) does not form craterform lesions in the liver and is active above $20^{\circ} \mathrm{C}$. HTPLO can be transmitted horizontally by cohabitation, and cold stress induces the syndrome in juvenile tilapia from farms where the disease is endemic.
\end{abstract}

KEY WORDS: Piscirickettsia-like · Rickettsia-like · Tilapia $\cdot$ Emerging disease $\cdot$ Piscirickettsiosis · Sarotherodon · Oreochromis

\section{INTRODUCTION}

Piscirickettsia salmonis was the first Rickettsia-like organism (RLO) recognized as a fish pathogen (Fryer et al. 1992). Since its identification, numerous microscopic observations and field isolations of RLOs have taken place worldwide in a variety of piscine species (Rodger \& Drinan 1993, Khoo et al. 1995, Jones et al. 1998). Many of these agents have been identified as $P$. salmonis by serologic and DNA sequencing methods (Evelyn 1992, Olsen et al. 1997, Jones et al. 1998); how- ever, other agents did not react with anti-P. salmonis antibodies in serologic assays and have not yet been subjected to DNA sequence analysis (S. C. Chen et al. 1994, 2000, Chern \& Chau 1994). Thus the relatedness of these disease agents to $P$. salmonis remains unknown, and they are best referred to as Piscirickettsia-like organisms (PLOs). Epizootics caused by $P$. salmonis or PLOs are often severe, resulting in high mortality and economic losses: P. salmonis-related losses were so severe in Chile that the Chilean aquaculture industry shifted production from the commer- 
cially desirable but highly $P$. salmonis-susceptible coho salmon Oncoryhnchus kisutch to the less susceptible and commercially less desirable Atlantic salmon Salmo salar (P. Smith, University of Chile, pers. comm.).

Emerging diseases caused by Piscirickettsia salmonis and related PLOs with significant economic losses have been increasing for the last 5 to $10 \mathrm{yr}$ in British Columbia (Brocklebank et al. 1992, Evelyn 1992) and Ireland (Rodger \& Drinan 1993). PLOs have also been observed in black seabass Dicentrarchus labrax in Europe (Comps et al. 1996, Athanassopoulou et al. 1999) and have been isolated from white seabass Atractoscion nobilis in California (M. F. Chen et al. 2000) during epizootics characterized by high mortalities and severe economic losses. In Taiwan, 37 aquaculture farms were affected with tilapia mortality, up to $95 \%$ in severe cases (Chen et al. 1994, Chern \& Chao 1994). In Hawaii, PLOs have caused significant losses on certain farms, and the transportation of fish between Oahu and the rest of the Hawaiian Islands is now restricted. In the last 18 mo our laboratory has examined tissues of tilapia from facilities in Jamaica, Indonesia, Florida and southern California that were experiencing Piscirickettsia-like epizootics. Gross and histologic lesions of these specimens were consistent with the syndrome associated with Hawaiian tilapia PLO (HTPLO). In this report, the clinical signs, gross and histologic lesions, diagnosis and treatment of piscirickettsiosis-like disease in Hawaiian tilapia are described.

\section{MATERIALS AND METHODS}

Microbiology. Tissues from naturally or experimentally infected and control tilapia (spleen, kidney, gill, brain, ovary, testis, muscle, blood and liver) were aseptically collected and inoculated onto tryptic soy agar (TSA), TSA with $5 \%$ bovine blood, Sabouraud's dextrose agar, Lowenstein-Jensen medium and mycoplasma medium. Inoculated media were incubated at room temperature $\left(20\right.$ to $22^{\circ} \mathrm{C}$ ) and at 16 to $18^{\circ} \mathrm{C}$ for $10 \mathrm{~d}$, except for the Lowenstein-Jensen medium, which was incubated at room temperature for 4 mo. Duplicate inoculated TSA $+5 \%$ bovine blood media was also incubated in $5 \% \mathrm{CO}_{2}$ for $10 \mathrm{~d}$. Tilapia tissues were homogenized in 10 volumes of minimal essential media (MEM), centrifuged at $200 \times g$ for $10 \mathrm{~min}$, and the supernatant inoculated onto several fish cell lines (Chinook salmon embryo 214, CHSE 214; epithelioma papulosum cyprini, EPC; fathead minnow, FHM; tilapia heart, TMB-8). All cell cultures were maintained with antibiotic-free MEM with $10 \% \mathrm{FBS}$ and were incubated at $16^{\circ} \mathrm{C}$ for $2 \mathrm{mo}$. The media was replaced weekly, at which time sub-culture onto fresh cells was attempted.
Histology. The spleen, kidney, gill, brain, ovary, testis, muscle, liver, other internal organs and often the whole euthanized fish $(\leq 6 \mathrm{~cm})$ were fixed in $10 \%$ buffered formalin. Paraffin sections were stained with haematoxylin and eosin (H\&E), Gram, Giemsa, Lillie Twort, Kinyoun's acid fast, Brown \& Brenn, Prussion Blue or Fontana Masson and observed by light microscopy. Smears of blood taken from the caudal vein were fixed in acetone for $10 \mathrm{~min}$, stained with Giemsa and observed by light microscopy.

Areas with lesions were removed from paraffinembedded tissues, deparaffinized with xylene, rehydrated via a graded series of alcohol into $0.01 \mathrm{M}$ phosphate buffer $\mathrm{pH} 7.3$, fixed in $1 \%$ osmium in phosphate buffer, dehydrated via a graded series of alcohol, infiltrated with Spurr's epoxy resin via propylene oxide, sectioned, stained with uranyl acetate and Reynold's lead citrate and observed with a Zeiss EM 900 transmission electron microscope.

Molecular and immunodiagnostics. Tissues were prepared, DNA extracted, and Piscirickettsia salmonisspecific PCRs were performed as previously described (Mauel et al. 1996) using P. salmonis LF-89 DNA as the positive control. Tissue sections and tissue impressions were prepared and $P$. salmonis-specific indirect fluorescent antibody (IFA) tests were performed as previously described (Lannan et al. 1991). Anti-P. salmonis rabbit serum was provided by J. L. Fryer (Oregon State University). Tissues from naive tilapia were spiked by immersion and injection with $P$. salmonis LF-89 tissue culture supernatant and used as positive controls for the FA tests.

Clinical trials. Transmission by cohabitation: Hawaii: Two circular 3001 tanks with $300 \%$ exchange of freshwater per $24 \mathrm{~h}$ and aeration were set up at the Anuenue Fisheries Research Center (AFRC), Oahu, Hawaii. Twenty sub-adult (30 to $60 \mathrm{~g}$ ) tilapia, from the Nuuanu Reservoir, Oahu, were transported to the center, and 10 fish were placed in each tank. One group was designated the control and the other the exposed. Water temperature in the tanks was monitored continuously by Hobo temperature data loggers. On Days 2 and 3 a single HTPLO-symptomatic tilapia (2 fish total) was released into the exposed tank. Fish in both tanks were fed a commercial pelleted ration and observed daily. Moribund and dead fish were removed, necropsy performed on each fish, and the spleen and other tissues harvested, preserved in Davidson fixative, processed, sectioned and stained with H\&E.

Tifton: Naive sub-adult tilapia (30 to $60 \mathrm{~g}$ ) from a commercial farm in Florida, USA, were placed in $10 \times$ 20 gal ( 761) aquaria (30 fish per aquarium) with aeration and $500 \%$ exchange of well water maintained between 21 and $23^{\circ} \mathrm{C}$ per $24 \mathrm{~h}$. Two of the aquaria were designated as controls. Fish were acclimated for 
$1 \mathrm{wk}$. The caudal fins of the naive tilapia were clipped for identification. Two symptomatic HTPLO tilapia from Hawaii were added to each experimental aquarium. Three random fish and any mortalities were removed daily from each aquarium, blood drawn from the caudal vein, and the live fish euthanized. Tissues were processed for histopathology and electron microscopy. Blood, spleen and kidney from each fish were inoculated onto cultured fish cells (CHSE 214, EPC, FHM, TMB-8) and observed as described previously.

Oxytetracycline feed trial: In Hawaii, $4 \times 3001$ circular tanks with $300 \%$ exchange of water per $24 \mathrm{~h}$, and aeration were set up at AFRC. Water temperature was monitored continuously by Hobo temperature data loggers. One hundred and fifty juvenile tilapia (average weight $10 \mathrm{~g}$ ) were collected from the Nuuanu Reservoir, divided into 2 groups, and each group placed in a 3001 tank. Fish were acclimated for 2 wk. One tank was fed Moore Clark ${ }^{\mathrm{TM}}$ (MC) feed. Fish in the other tank were fed Rangen $^{\mathrm{TM}}$ feed fortified with $4.0 \mathrm{~g}$ of oxytetracycline (OTC) per pound ( 2.2 kg). The fish were then further divided into 4 groups of 30 to 32 fish each and placed in separate 3001 tanks. The treatment groups were MC control, MC exposed, OTC control and OTC exposed. Throughout the trial tilapia were fed and observed daily, and any dead or moribund fish were removed. Dead and moribund fish were necropsied and tissues preserved in Davidson fixative. The trial was run for $20 \mathrm{~d}$, and on Day 2, 3 HTPLO symptomatic fish were released into the 2 exposed tanks. On Day 20 all remaining fish were sacrificed and tissues preserved in Davidson fixative, sectioned and stained with H\&E.

Avian fecal transmission of PLO: In Hawaii, $2 \times 3001$ tanks were set up as described earlier, and 20 Nuuanu juvenile tilapia were placed in each tank. On 6 consecutive days a piscivorous bird was fed between 12 and 15 moribund or freshly dead juvenile tilapia that had died of HTPLO infection. The bird was housed in a cage with a plastic sheet lining the bottom. On the morning after each infectedtilapia feeding, the plastic sheet with the feces was removed, the feces collected and placed in the exposed tank and the tank water turned off for $3 \mathrm{~h}$.

Temperature as a factor in $\mathrm{PLO}$ infections: In Hawaii, juvenile tilapia originating from brood stock from an area believed to be endemic for HTPLO were placed into $2 \times 25 \mathrm{gal}$ ( 951) aquaria (250 fish per tank). The tanks had $300 \%$ exchange of water per $24 \mathrm{~h}$ and aeration. One tank was placed in an area where water temperature was warm, and the other where the water was cooled by exposure to strong trade winds. A Hobo temperature data logger was placed in each tank. The tilapia had been raised in the warm location. The fish were fed a commercial pelleted ration.

\section{RESULTS}

The initial cases of HTPLO disease in Hawaii were encountered in October 1994 in moribund tilapia collected from wild populations in natural bodies of water on Oahu. Eventually losses exceeding $60 \%$ in farmed tilapia on Oahu were not unusual. Tilapia were the only fish affected.

\section{Pathology field cases}

Affected fish in all locations displayed similar clinical signs and lesions. Infected tilapia were pale, sometimes emaciated, often swam erratically, and appeared to have difficulty staying at depth. At necropsy, occasional cutaneous haemorrhage and exophthalmia were noted, as were enlarged spleens ( $\sim 5$ to 25 times normal) with multiple white granulomas (Fig. 1). Histologically, granulomas and mixed inflammatory infiltrates composed of mononuclear cells and acidophils were observed in many tissues. The gills had epithelial hyperplasia, with severe fusion of secondary lamellae (Fig. 2) and loss of intralamellar spaces. Granulomatous proliferative response was often present at the base of the gill arch. Hepatic lipidosis was noted frequently.

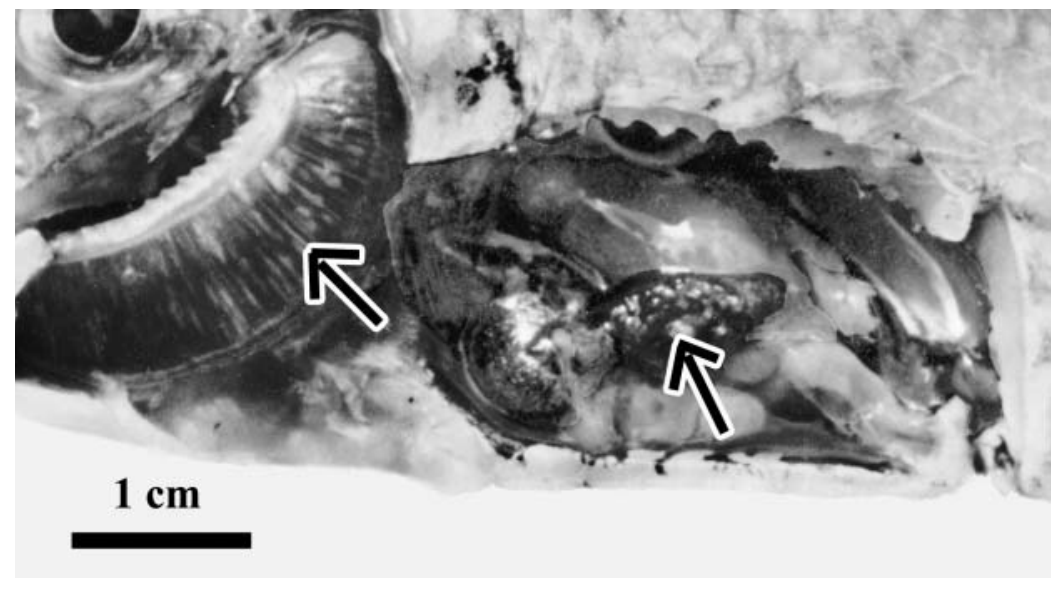

Fig. 1. Sarotherodon melanotheron. An adult black-chinned tilapia S. melanotheron with the gross changes of the severe, chronic stage of the Hawaiian tilapia Piscirickettsia-like organism (HTPLO) disease. Note the granulomas in the gills and in the spleen (arrows) 


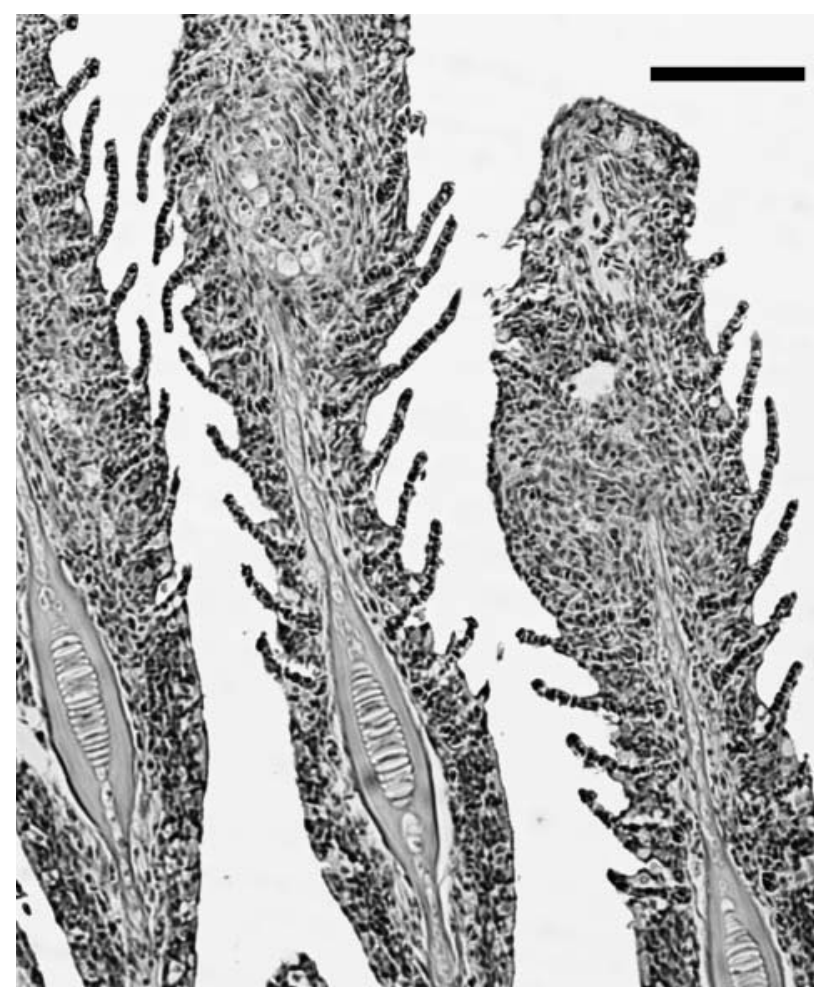

Fig. 2. Sarotherodon melanotheron. Photomicrograph of primary and secondary gill lamellae from tilapia with early acute signs of the Hawaiian tilapia Piscirickettsia-like organism (HTPLO). Note hyperplasia, and severe consolidation of secondary lamellae. Scale bar $=50 \mu \mathrm{m}$

\section{Bacteriology}

No bacterial species were consistently grown on any of the artificial media. No growth was observed on the Lowenstein-Jensen media. No cytopathic effect (CPE) was noted in any of the cell cultures. Some degradation of the cell monolayer was present in several initial cultures, but no degradation was observed when spent media was sub-cultured to fresh cells.

\section{Molecular and immunodiagnostics}

Fluorescence was evident up to serum dilutions of 1:1024 with the Piscirickettsia salmonis-positive control tissues. No fluorescence was observed when spleens from infected tilapia were assayed by P. salmonis-specific IFA (data not shown). An amplification product was obtained from the $P$. salmonis LF-89 DNA; however, no amplification product was recovered from the HTPLO with $P$. salmonis-specific PCR (data not shown).

\section{Histopathology}

In the transmission-by-cohabitation trials in Tifton, $24 \mathrm{~h}$ after exposure by cohabitation to the HTPLO, the spleen of the naive tilapia was infiltrated with scattered melanomacrophages (verified by positive staining with Fontana Mason) that increased in number with time. By $48 \mathrm{~h}$ post-exposure, a mild granulomatous inflammatory infiltrate was evident in the spleen and gills. Haemorrhage was minimal to mild. After 72 h, Prussian blue stains revealed moderate amounts of haemosiderin. Discrete granulomas were found in multiple organs including anterior and posterior kidney, spleen, gills, and choroid gland (Fig. 3). The liver was involved only late in the course of infection (Day 7), and a discrete hepatic granuloma was only observed once.

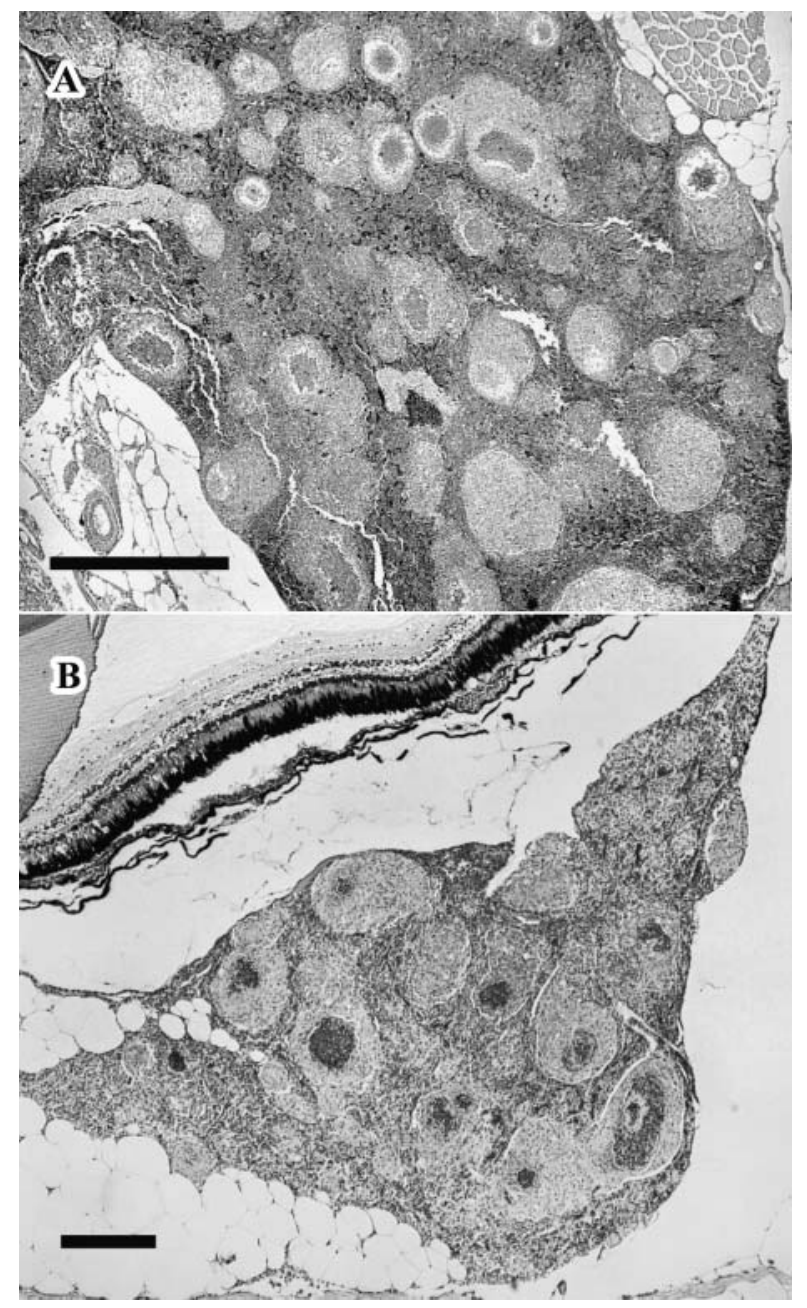

Fig. 3. Photomicrographs of the the Hawaiian tilapia Piscirickettsia-like organism (HTPLO) in H\&E-stained Sarotherodon melanotheron spleen (A) and choroid gland (B). Note the numerous granulomas. Scale bars $=50 \mu \mathrm{m}(\mathrm{A})$ and $25 \mu \mathrm{m}$ (B) 
Granulomas consisted of large, foamy, vacuolated macrophages encircled by thin fibrous capsules and small cuffs of lymphocytes with few acidophils (Fig. 4). The center of the granuloma was often completely necrotic or had small areas of necrosis associated with individual or small clusters of pleomorphic coccobacilli. In late infection (>7 d), granulomas and histiocytic inflammation were often confluent to diffuse.

The organisms were inconsistently visualized with Giemsa and Warthin-Starry stains (Fig. 5), stained poorly with Brown \& Brenn, but stained red with Lillie Twort and were basophilic with H\&E stains. No organisms were observed in any sections stained with Kinyoun's Acid Fast stain. In blood smears, moderate to large numbers of bacteria were noted within rare circulating monocytes.

In ultrathin sections, Pleomorphic, generally coccoid, bacterial organisms $(0.56 \pm 0.14 \times 0.7 \pm 0.20 \mu \mathrm{m})$ were observed free in the cytoplasm and within phagolysosomes (Fig. 6A). The organisms had a double cell wall with no defined nucleus and variable electron dense and electron-lucent areas (Fig. 6B,C).

\section{Clinical trials: transmission by cohabitation}

In Hawaii, by Day 5 after the initial introduction of the HTPLO fish, the 2 symptomatic fish had died and been removed. Histological examination of the spleens of the 2 symptomatic fish demonstrated multiple granulomas indicative of HTPLO infection. The onset of HTPLO mortality was on Day 11 in the exposed group. When the experiment was terminated on Day 23, mortality was $70 \%$ in the exposed group and $0 \%$ in the control group. All tilapia in the exposed group demonstrated multiple granulomas indicative of HTPLO infection in the spleen, by gross and histopathology. No signs of HTPLO infection were observed in the control group grossly or by histopathology. The mean $\pm \mathrm{SD}$ for the water temperature was $22.32 \pm 0.19$ and $21.78 \pm$ $0.25^{\circ} \mathrm{C}$, respectively, for the control and exposed tanks.

\section{Oxytetracycline feed trial}

In Hawaii, all HTPLO-symptomatic fish placed in the exposed tanks had died and been removed by Day 5 . The onset of mortality was on Day 13 in the MC exposed group. Survival was $97 \%$ in the OTC control group, $100 \%$ in the MC control group, $83 \%$ in the OTC exposed group and $17 \%$ in the MC exposed group. No fish in the 2 control groups exhibited any gross or histological lesions of HTPLO infection. In the MC exposed group, $60 \%$ (3 fish) of the survivors had histologic lesions of HTPLO infection, while in the OTC exposed group, $40 \%$
(10 fish) had histologic lesions of HTPLO infection. All tilapia that died during the trial exhibited systemic granulomas of HTPLO infection, with the exception of 1 fish from the OTC control group that died on Day 14. The mean water temperature was: MC control, $22.49 \pm$ $0.183^{\circ} \mathrm{C}$; $\mathrm{MC}$ exposed, $22.51 \pm 0.249^{\circ} \mathrm{C}$; OTC control, $22.64 \pm 0.735^{\circ} \mathrm{C}$; and OTC exposed, $22.51 \pm 0.162^{\circ} \mathrm{C}$.

\section{Avian fecal transmission of PLO}

In Hawaii, survival was $100 \%$ in the bird-feces exposed group and $95 \%$ in the control group. No gross or histological evidence of HTPLO infection was found in any fish. The mean \pm SD temperature was $22.58 \pm$ $0.241^{\circ} \mathrm{C}$ in the exposed group.

\section{Temperature as a factor in PLO infections}

In Hawaii, the water temperature averaged $24.45^{\circ} \mathrm{C}$ in the cold location and $26.96^{\circ} \mathrm{C}$ in the warm location. The water temperature fluctuated (diurnal cycle) between 26.5 and $29.2^{\circ} \mathrm{C}$ in the warm tank and between 21.5 and $26.3^{\circ} \mathrm{C}$ in the cold tank. Mortalities were first observed in the cold tank on Day 15 and progressed by doubling daily thereafter. The trial was halted on Day 24 with $4 \%$ survival in the cold treatment group. No tilapia died in the warm treatment group. Samples of fish taken on Days 15 and 21 from the cold treatment group were found to have histologic lesions consistent with HTPLO infection. No HTPLO lesions were found in a sample of control fish collected on Day 21.

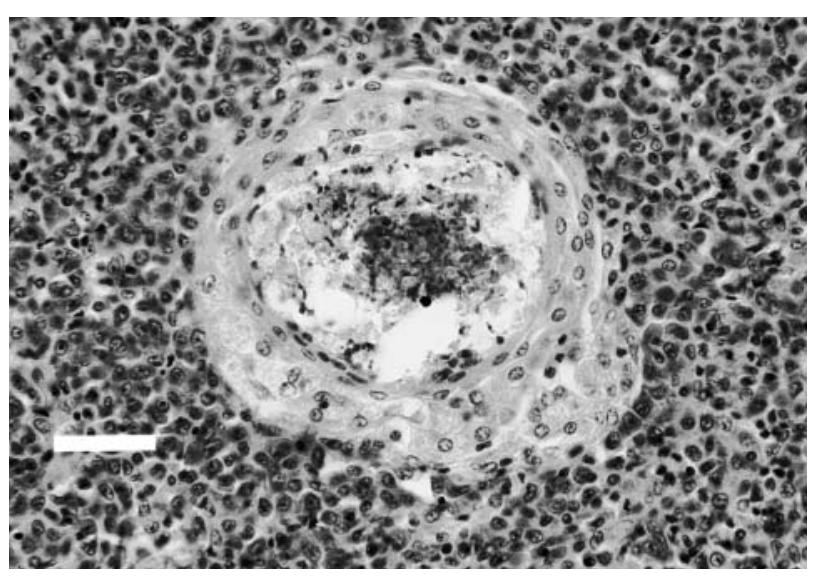

Fig. 4. Photomicrograph of a discreet granuloma from a tilapia Sarotherodon melanotheron experimentally infected with the Hawaiian tilapia Piscirickettsia-like organism (HTPLO) showing the large foamy macrophages and fine fibrous capsule surrounding central areas of necrosis (arrow). Scale bar $=50 \mu \mathrm{m}$ 


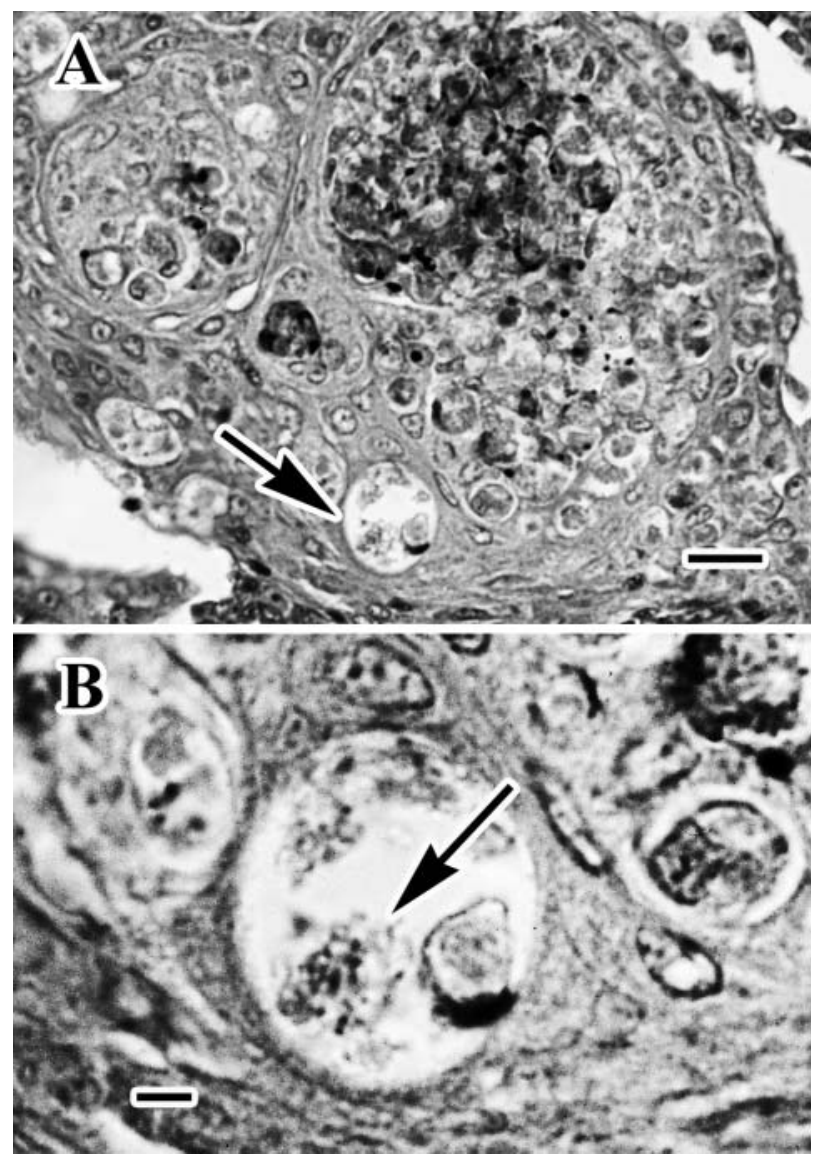

Fig. 5. Photomicrograph of granulomatous inflammation in the spleen of experimentally infected tilapia Sarotherodon melanotheron (Lillie Twort). (A) Location of a vacuolated cell within a granuloma. Scale bar $=50 \mu \mathrm{m}$. (B) High-power view of the intracellular vacuole containing the Hawaiian tilapia Piscirickettsia-like organism (HTPLO) bacteria (arrow). Scale bar $=10 \mu \mathrm{m}$

\section{DISCUSSION}

The Hawaiian tilapia Piscirickettsia-like organism has many characteristics in common with P. salmonis. Both show characteristics including: they are obligate intracellular bacterial pathogens of fish; pleomorphic coccoid bacteria, occurring free in the cytoplasm and within phagolysosomes; they have a double cell wall with no defined nucleus and variable electron-dense and electron-lucent areas. In contrast to P. salmonis, the HTPLO is $0.56 \pm 0.14 \times 0.7 \pm 0.20 \mu \mathrm{m}$ while $P$. salmonis is larger at $0.5 \times 1.2 \mu \mathrm{m}$. The disease syndromes caused by the 2 bacteria are also similar, although the hepatic lesions seen with $P$. salmonis in salmon have not been observed in tilapia. Epizootics of P. salmonis occur most frequently between 9 and $16^{\circ} \mathrm{C}$ (Cvitanich et al. 1991) while the HTPLO produces dis- ease up to $24^{\circ} \mathrm{C}$. The HTPLO does not respond to $P$. salmonis-specific antibodies in an IFAT and does not produce an amplicon with a P. salmonis-specific PCR. The differences in size, host, active temperature, genetics, pathology and antigenic variance leads us to conclude that the HTPLO is not $P$. salmonis, but should be considered a Piscirickettsia-like bacterium.

The HTPLO falls within the size range of the PLO found in tilapia in Taiwan $(0.63 \pm 0.24 \times 0.86 \pm 0.32 \mu \mathrm{m}$;

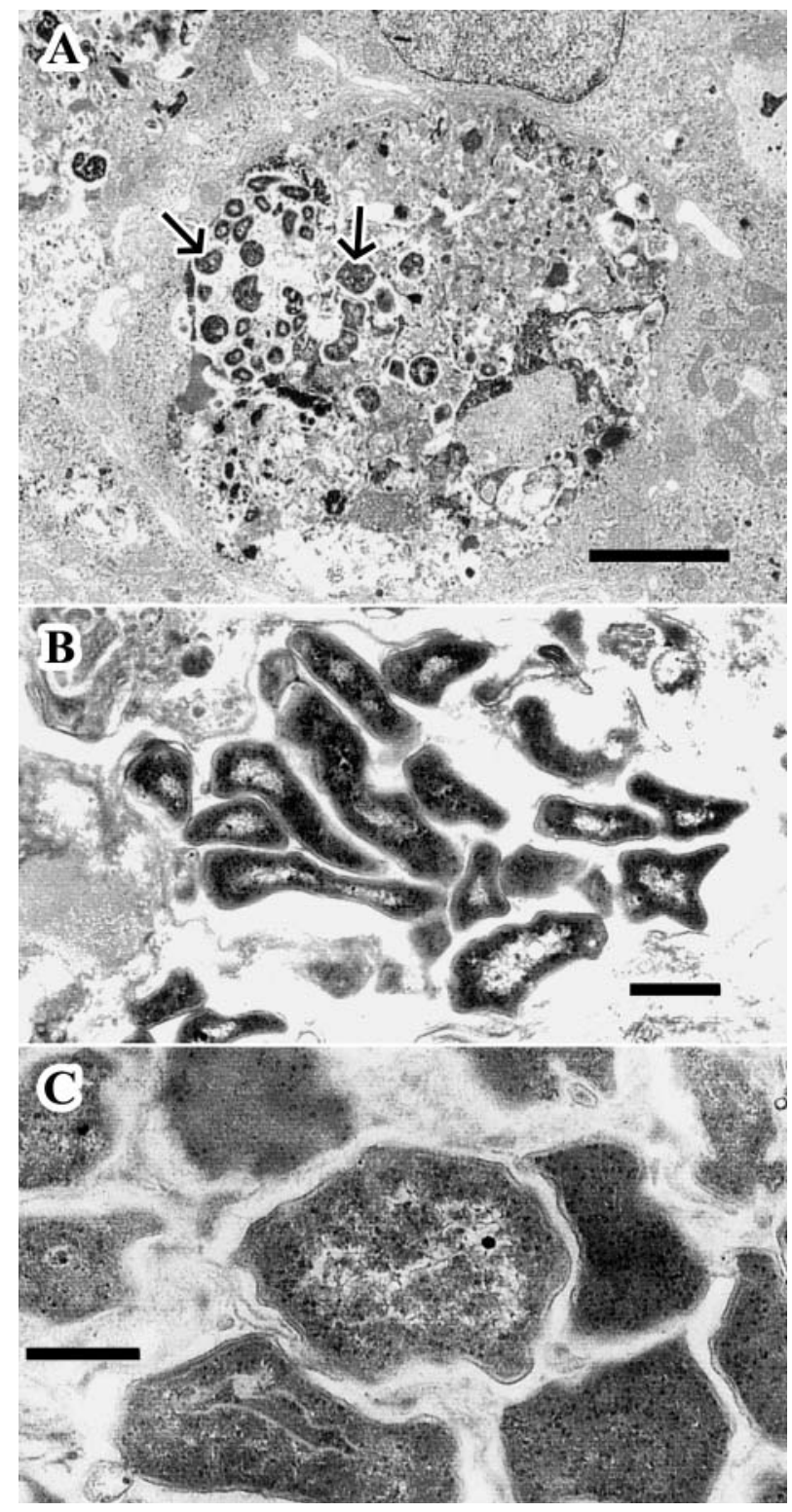

Fig. 6. (A) Ultrathin section of the the Hawaiian tilapia Piscirickettsia-like organism (HTPLO) (arrows) associated with necrotic cellular debris within a phagosome in a splenic macrophage. Scale bar $=3 \mu \mathrm{m}$. (B) and (C) Ultrathin sections of pleomorphic HTPLO in small micro-colonies within phagosomes in the spleen. Scale bars $=0.5 \mu \mathrm{m}(\mathrm{B})$ and $0.3 \mu \mathrm{m}(\mathrm{C})$ 
Chern \& Chau 1994). The clinical signs are similar, with the exception of liver lesions that were common in the Taiwan PLO infections but were not evident in the Hawaiian PLO infections until the later stages of the disease (Chen et al. 1994, Chern \& Chau 1994). Chern \& Chau (1994) were able to culture the bacteria on tilapia ovary (TO-2) and EPC cell lines with resulting CPE (rounding of cells). Chen et al. (1994) were able to isolate the bacteria on CHSE 214 cells. Although no CPE was observed, organisms were found in cell cytoplasm. In contrast, organisms could not be cultured in FHM, BF-2 or TO-2 cell lines. As in our study, Chern \& Chau (1994) found that oral oxytetracycline therapy reduced mortality.

The cohabitation trial in Hawaii demonstrated that the HTPLO was transmitted to HTPLO-free fish by contact exposure with HTPLO-infected fish. The trial revealed that tilapia from the Nuuanu Reservoir were free of HTPLO and highly sensitive to infection and disease when exposed. The OTC trial indicates that feeding tilapia OTC-medicated feed, especially if the treatment is started prior to the onset of mortality, can dramatically improve survival of the fish when the tilapia are exposed to PLO. No evidence was found to support bird feces as a vector of HTPLO in tilapia.

The temperature trial established that prolonged $(>1 \mathrm{wk})$ exposure to low water temperature is a permissive factor for expression of PLO infection in tilapia. Also, at warmer water temperatures, HTPLO apparently occurs in tilapia as a subclinical infection, although the disease is expressed when the hosts are exposed to a stressor such as low water temperature. In our study, $10 \mathrm{~d}$ of exposure to water fluctuating between 21.5 and $26.3^{\circ} \mathrm{C}$ was sufficient to induce active HTPLO disease. This model could be utilized to test asymptomatic stocks of tilapia for the presence of HTPLO before transferring them to HTPLO-free areas.

At this time, it is apparent that the geographic distribution of Piscirickettsia-like agents is wide, their host range is broad, and the potential impact of PLOs on fish health is extensive. Many of these bacteria cause epizootics in non-salmonid fish and produce severe mortality in affected fish species (80 to 95\%). Piscirickettsiosis-like syndromes are an emerging disease that poses a major threat to the aquaculture industry. An understanding of the characteristics of the bacteria and the disease syndrome is vital in developing effective prevention and control strategies.

Editorial responsibility: David Bruno, Aberdeen, Scotland, UK

\section{LITERATURE CITED}

Athanassopoulou F, Sabatakou O, Groman D, Prapas TH (1999) First incidence of rickettsia-like infections in cultured seabass (Dicentrarchus labrax L.) in Greece. Poster Abstract, 9th Int Conf Eur Assoc Fish Pathol, September 19-14, 1999, Rhodes

Brocklebank JR, Speare DJ, Armstrong RD, Evelyn T (1992) Septicemia suspected to be caused by a rickettsia-like agent in farmed Atlantic salmon. Can Vet J 33:407-408

Chen MF, Yun S, Marty GD, McDowell TS and 5 others (2000) A Piscirickettsia salmonis-like bacterium associated with mortality of white seabass Atractoscion nobilis. Dis Aquat Org 43:117-126

Chen SC, Tung MC, Chen SP, Tsai JF, Wang PC, Chen RS, Lin SC, Adams A (1994) Systemic granulomas caused by a rickettsia-like organism in Nile tilapia, Oreochronuis niloticus (L.), from southern Taiwan. J Fish Dis 17:591-599

Chen SC, Wang PC, Tung MC, Thompson KD, Adams A (2000) A Piscirickettsia salmonis-like organism in grouper, Epinephelus melanostigma, in Taiwan. J Fish Dis 23:415-418

Chern RS, Chao CB (1994) Outbreaks of a disease caused by a rickettsia-like organism in cultured tilapias in Taiwan. Fish Pathol 29:61-71

Comps M, Raymond JC, Plassiart GN (1996) Rickettsia-like organism infecting juvenile sea-bass Dicentrarchus labrax. Bull Eur Assoc Fish Pathol 16:30-33

Cvitanich, JD, Garate NO, Smith CE (1991) The isolation of a rickettsia-like organism causing disease and mortality in Chilean salmonids and its confirmation by Koch's postulate. J Fish Dis 14:121-145

Evelyn TPT (1992) Salmonid rickettsial septicemia. In: Kent ML (ed) Diseases of seawater netpen-reared salmonid fishes in the Pacific Northwest. Can Spec Pub Fish Aquat Sci 116. Department of Fisheries and Oceans, Nanaimo, British Columbia, p 18-19

Fryer JL, Lannan CN, Giovannoni SJ, Wood ND (1992) Piscirickettsia salmonis gen. nov., sp. nov., the causative agent of an epizootic disease in salmonid fishes. Int J Syst Bacteriol 42:120-126

Jones SRM, Markham RJF, Groman DB, Cusack RR (1998) Virulence and antigenic characteristics of a cultured Rickettsiales-like organism isolated from farmed Atlantic salmon Salmo salar in eastern Canada. Dis Aquat Org 33:25-31

Khoo L, Dennis PM, Lewbart GA (1995) Rickettsia-like organisms in the blue-eyed plecostomus, Panaque suttoni (Eigenmann \& Eigenmann). J Fish Dis 18:157-164

Lannan CN, Ewing SA, Fryer JL (1991) A fluorescent antibody test for detection of the rickettsia causing disease in Chilean salmonids. J Aquat Anim Health 3:229-234

Mauel MJ, Giovannoni SJ, Fryer JL (1996) Development of polymerase chain reaction assays for detection, identification, and differentiation of Piscirickettsia salmonis. Dis Aquat Org 26:189-195

Olsen AB, Melby HP, Speilberg L, Evensen O, Hastein T (1997) Piscirickettsia salmonis infection in Atlantic salmon Salmo salar in Norway-epidemiological, pathological and microbiological findings. Dis Aquat Org 31:35-48

Rodger HD, Drinan EM (1993) Observation of a rickettsia-like organism in Atlantic salmon, Salmo salar L., in Ireland. J Fish Dis 16:361-369

Submitted: January 23, 2002; Accepted: October 11, 2002 Proofs received from author(s): February 7, 2003 